\title{
Self Perceptions as Predictors for Return to Work 2 Years After Rehabilitation in Orthopedic Trauma Inpatients
}

\author{
Maria Iakova $\cdot$ Pierluigi Ballabeni $\cdot$ \\ Peter Erhart • Nikola Seichert • François Luthi • \\ Olivier Dériaz
}

Published online: 5 May 2012

(C) The Author(s) 2012. This article is published with open access at Springerlink.com

\begin{abstract}
Purpose This study aimed to identify self-perception variables which may predict return to work (RTW) in orthopedic trauma patients 2 years after rehabilitation. Methods A prospective cohort investigated 1,207 orthopedic trauma inpatients, hospitalised in rehabilitation, clinics at admission, discharge, and 2 years after discharge. Information on potential predictors was obtained from self administered questionnaires. Multiple logistic regression
\end{abstract}

Maria Iakova and Pierluigi Ballabeni have equally contributed to this work.

M. Iakova $(\bowtie) \cdot$ F. Luthi

Département de l'appareil locomoteur, Clinique Romande de Réadaptation SUVA Care, Avenue Grand-Champsec 90,

1951 Sion, Switzerland

e-mail: maria.iakova@crr-suva.ch

P. Ballabeni · O. Dériaz

Research Department, Clinique Romande de Réadaptation

SUVA Care, Sion, Switzerland

P. Ballabeni · F. Luthi · O. Dériaz

Institut de recherche en réadaptation et Service de recherche médicale, Clinique Romande de Réadaptation SUVA Care, Sion, Switzerland

P. Ballabeni

Institute of Social and Preventive Medicine (IUMSP), Centre

Hospitalier Universitaire Vaudois, University of Lausanne,

Lausanne, Switzerland

P. Erhart · N. Seichert

Department of Vocational Rehabilitation, Rehaklinik Bellikon,

Bellikon, Switzerland

F. Luthi

Département de l'appareil locomoteur, Centre Hospitalier Universitaire Vaudois, University of Lausanne, Lausanne, Switzerland models were applied. Results In the final model, a higher likelihood of RTW was predicted by: better general health and lower pain at admission; health and pain improvements during hospitalisation; lower impact of event (IES-R) avoidance behaviour score; higher IES-R hyperarousal score, higher SF-36 mental score and low perceived severity of the injury. Conclusion RTW is not only predicted by perceived health, pain and severity of the accident at the beginning of a rehabilitation program, but also by the changes in pain and health perceptions observed during hospitalisation.

Keywords Return to work - Injury - Accident - Pain . PTSD · IES-R

\section{Background}

After traumatic injury, most patients will generally return to work within a few weeks. However, the majority of the costs will be caused by the few remaining workers with long term sick leaves [1]. For this reason, it is important for clinicians to identify, as early as possible, workers at high risk for disability in order to facilitate intervention strategies [1].

No consensus exists in the literature and various prognostic factors have been proposed (for a review see [2]). However, there is increasing evidence that the return to work may be predicted by some variables like education, gender, blue collar, injury severity, number of surgical procedures and self-efficacy (psychological factors) [2]. The earliest studies, based on biomedical variables failed to predict RTW [3]. This prompted the development of biopsychosocial models (BPS) $[4,5]$ which aims to analyze the multidimensional nature of the problem and several 
predictors have been proposed. Work-ability, which is linked to return to work, depends on factors related to the patient (physical, psychological, cognitive, and behavioural factors) but also to the environment (social, workplace factors and factors outside the workplace) [6]. Taking all these results together, it appears that psychosocial factors are of primary importance. For instance, subjective perception of pain, self-assessment of physical status [7], patient beliefs [8] and catastrophising $[9,10]$ as well as fear avoidance [11] are good predictors of disease chronicity and, consequently, RTW. Finally, post traumatic stress disorder (PTSD), which was initially studied in soldiers, is also present in patients with musculoskeletal trauma (for a review see [12]) and some studies have shown that PTSD is associated with return to work in patients with hand injury $[13,14]$ and burns [15] but these results were not reproduced by others in trauma patients [16]. This important issue remains to be investigated more thoroughly.

It can be postulated that the changes in prognostic factors, induced by a rehabilitation program (i.e. pain, psychological variables etc.), are good indicators of the patient's response to the treatment and, consequently, may improve his/her outcome. This hypothesis is confirmed by few prospective studies in which changes in pain, perceived health/disability, related to the treatment, predicted return to work $[17,18]$. However, this issue remains, to our knowledge, largely unexplored.

With the present prospective cohort study, we intended to investigate whether a number of baseline self-perception variables may predict return to work 2 years after orthopedic and vocational rehabilitation for orthopedic trauma. For this purpose, we analyzed data from patients recruited into a cohort called OUTCOME, started in two Swiss rehabilitation clinics with the aim of assessing quality of life and work status outcomes after rehabilitation [19].

\section{Methods}

\section{Study Design}

A prospective cohort study was conducted, in which selfadministered questionnaires were used at admission into rehabilitation clinic, then at discharge and 2 years after discharge.

\section{Population}

We included in this study patients with orthopedic trauma of the back and upper and lower limb, hospitalised in two Swiss rehabilitation clinics between 15 November 2003 and 31 December 2005. The clinics were the French speaking Clinique Romande de Réadaptation (CRR) at
Sion, and the German speaking Rehaklinik Bellikon (RKB) at Bellikon. All patients hospitalised for a rehabilitation program after a traumatic injury were eligible for the OUTCOME study, if they had no severe traumatic brain injury (Glasgow coma scale $\leq 8$ ), had no spinal cord injury, were capable of judgment, were not under legal custody and were not older than 60 years (considered as too old to have a reasonable chance to RTW). Most of our inpatients were blue collar workers and took part in a rehabilitation program after work, leisure or traffic accidents. Patients were sent to the rehabilitation hospitals when they presented persistent pain and functional limitations after an accident (median: 9 months after the accident). The aim of the therapeutic program is to take care of patients with an interdisciplinary approach (somatic, psychological and social) in order to reduce disabilities and improve chance of returning to work (usual or adapted to impairments).

Patients signed an informed consent form before entering the study. The protocol was approved by the ethical committee of the local medical associations.

\section{Variables}

For the present analysis, baseline variables (predictors and confounders) were assessed by means of self-evaluation questionnaires filled in by the patients within 3 days after hospitalisation and 2 days before discharge. RTW status was assessed via a postal questionnaire sent 2 years after clinic discharge. The binary outcome was coded 1 if a subject had a job and 0 if a subject had no job.

The following variables were tested as potential predictors: (1) general health perceived at admission (visual analogue scale, VAS, scale range 0-100); (2) general health improvement during hospitalisation (VAS); (3) pain at admission (VAS, range 0-100); (4) pain decrease during hospitalisation (VAS); (5) anxiety score of Hospital Anxiety and Depression Scale (HADS) [20] at admission (range 0-21); (6) depression score of HADS at admission (range 0-21); (7) physical summary score of the Short Form of the Health Status measure, SF-36 [21] (range 0-100); (8) mental summary score of the SF-36 questionnaire (range 0-100); (9) avoidance score of the extended, 22 items, Impact of Event Scale (IES-R) [22, 23] (range 0-40); (10) intrusion score of the IES-R [22, 23] (range 0-40); (11) hyper-arousal score of the IES-R [22, 23] (range 0-30); (12) perceived severity of injury (binary variable: very light to moderate vs. severe to very severe); (13) perceived expected injury outcome (binary: soon recovered or getting better vs no recovery or worsening).

The analyses were adjusted for the following potential confounders, which are likely to be associated with the predictive variables and RTW: gender, age at admission (treated as continuous variable), clinic, native language 
(local language of the clinic location, i.e. French or German, versus other), marital status (living in stable partnership versus alone), educational level ( $\leq 9$ years vs. $>9$ years), time between accident and admission in clinic ( $<12$ months vs. $>12$ months), possession of a work contract at admission (yes vs. no), trauma localization : upper limb, lower limb, neck, low back (three binary dummy variables, with upper limb as the reference category).

\section{Statistical Analysis}

The associations between the binary outcome variable RTW at 2 years and the exposure variables were evaluated by means of logistic regression. We built statistical models as follows. First, predictors were tested individually, once alone and once adjusted by the confounders. Second, all predictors with $p \leq 0.25$ in the previous adjusted models were tested together and with the confounders in what we call a full model. Third, in a backward selection procedure, we dropped from the full model the predictor with the highest $p$ value. After dropping a predictor, the Akaike information criterion (AIC) was noted. AIC is a measure of how close outcomes predicted by a model are to the true expected outcomes and a lower AIC indicates a better model fit. This procedure was repeated until a group of predictors remained that could not be further reduced without increasing the AIC compared to the full model. At this point only predictors with $p<0.1$ remained in the model, which we call the minimal model. The previously dropped predictors were then individually added to the minimal model, to make sure that their effect remained statistically not significant $(p>0.1)$ and that their presence did not alter the effects of the minimal predictors of the minimal model, which became final.

The relationships between continuous predictors and confounders and the probability of RTW were found to be acceptably linear after comparing the deviances of models containing the best fractional polynomial transformations of these variables and those of models with untransformed variables [24]. Thus neither transformation nor recoding was needed to achieve linearity. However, continuous predictor variables were $\mathrm{z}$-score transformed, to produce odds-ratios related to comparable increments in different variables. A $\mathrm{z}$-score indicates the deviation from the variable's mean expressed as number of standard deviations.

The quality of our final model was assessed by the Hosmer-Lemeshow goodness of fit statistic [25] and the concordance index, also called c statistic. The $\mathrm{c}$ statistic is a measure of the predictive ability of a prognostic model and is equivalent to the area under the receiver operating characteristics (ROC) curve [25] In our analyses, the c statistic is the ability of a model to discriminate subjects with high probability of RTW from those with low probability. The $\mathrm{c}$ statistic ranges from 0.5 (no predictive discrimination) to 1 (perfect discrimination); values below 0.7 indicate a poor discrimination ability, values $0.7-0.8$ an acceptable discrimination, and values above 0.8 an excellent to outstanding discrimination. In general, prognostic models tend to produce higher c statistics in the dataset in which the model was developed than they will in future subjects. Therefore, to assess the internal validation of our final model we computed an optimism-corrected c statistic using bootstrapping [26].

Expecting medical and cultural differences between two clinics located in two different linguistic areas, we considered patients to be correlated within clinic. Therefore, a clustered sandwich estimator was used to estimate the variance-covariance matrix and the coefficients' standard errors in all regression models. This procedure affects only the standard errors but not the regression coefficients. The option vce (cluster) was used within the logistic command of the statistical package Stata. Stata version 11.2 was used for all calculations (StataCorp, College Station, TX, USA, www.stata.com).

\section{Results}

1,883 Patients participated in the Outcome cohort. After excluding subjects older than 60 years or with injury locations other than limbs or back, or with missing values for these variables, 1,207 patients were entered in the present study (Fig. 1). 665 (55\%) were recruited by the RKB and $542(45 \%)$ by the CRR.

At admission, the mean age of the 1,207 participants was 41 years, SD 11. The proportion of males was $81 \%$. Moreover, $55 \%$ of the patients spoke the local language (i.e. German or French), $53 \%$ were married or had a domestic partner and $47 \%$ were alone. $45 \%$ patients had more than 9 years education, $64 \%$ were in possession of a work contract. The sites of the injury were: $26 \%$ upper limb, $34 \%$ lower limb, $17 \%$ neck and $22 \%$ low back (Table 1).

At discharge, 171 patients did not respond to the investigation questionnaire and another 505 did not send back the 2-year questionnaire. Thus, 531 patients responded at 2 years, 411 of whom could be included in the final model having complete data (Fig. 1).

The values of the confounding variables did not change substantially between admission and 2 years post discharge with the exception of native language. The proportion of native speakers was $55 \%$ at admission, $68 \%$ at 2 years, and $75 \%$ of the complete cases (Table 1).

The values of the predictors did not change substantially between the admission set and the final analysis set (Table 2). 


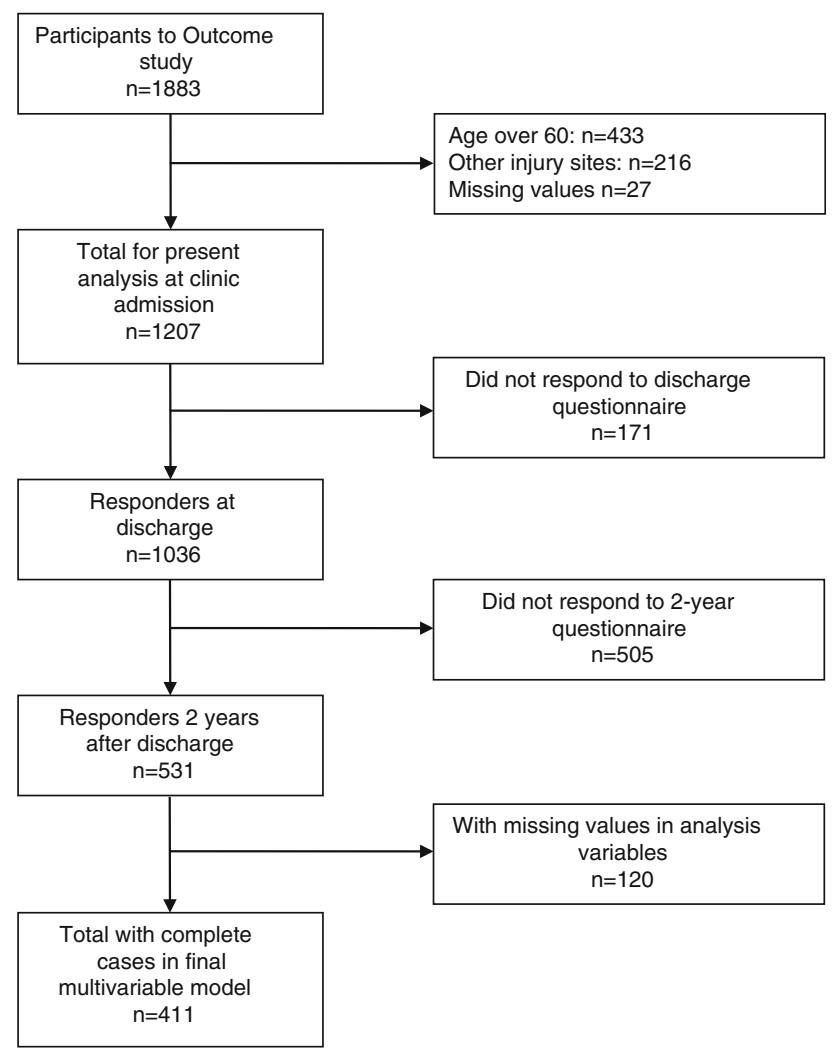

Fig. 1 Flow chart

Predictors of Return to Work

After the simple regressions and the regressions with the single predictors adjusted for the confounders, all predictors (except the interval between the accident and the hospitalisation) were used to build the full multiple regression model (Table 3). After the variable selection procedure, a final model containing eight variables was obtained (Fig. 2).

Among the subjects included in the final model, $238(58 \%)$ were back to work, while 173 (42\%) were not working. Compared to those not working, the subjects back to work had higher general health score at admission $($ mean $=52.9$, $\mathrm{SD}=20.6$, vs. mean $=43.9, \mathrm{SD}=22.7)$, higher general health improvement during stay (mean $=7.9, \mathrm{SD}=21.4$, vs. mean $=5.1, \mathrm{SD}=26.5$ ), lower pain score at admission $($ mean $=48.6, \mathrm{SD}=25.3$, vs. mean $=59.4, \mathrm{SD}=23.6$ ), higher pain decrease during stay (mean $=-9.1, \mathrm{SD}=23.7$, vs. mean $=-1.7, \mathrm{SD}=23.7$ ), higher SF-36 mental health score $\quad($ mean $=40.4, \quad \mathrm{SD}=9.5, \quad$ vs. $\quad$ mean $=37.4$, $\mathrm{SD}=8.3$ ), lower IES-R avoidance (mean $=9.1, \mathrm{SD}=9.9$, vs. mean $=13.9, \quad \mathrm{SD}=10.9$ ) and IES-R hyperarousal $($ mean $=8.9, \mathrm{SD}=8.2$, vs. mean $=12.4, \mathrm{SD}=8.4)$ scores and higher proportion perceiving injury severity as very light to moderate (46 vs. $31 \%$ ).
After controlling for the confounders, the data were compatible with higher chances of being at work for patients with a higher perceived general health at admission (OR $=1.48$ for 1-SD increments), although a lack of effect could not be excluded (see confidence interval). The chances of being at work were also higher for patients whose general health improved during stay ( $\mathrm{OR}=1.16$ for 1-SD increments), those with a higher SF-36 mental summary score $(\mathrm{OR}=1.09$ for each $\mathrm{SD})$, higher IES-R hyperarousal score $(\mathrm{OR}=1.13$ for each $\mathrm{SD})$ and those feeling their injury severity as very light to moderate $(\mathrm{OR}=1.11$ for comparison with severe to very severe) (Fig. 2).

On the contrary, patients with higher pain at admission $(\mathrm{OR}=0.59$ for each $\mathrm{SD}$ ), pain increase during stay $(\mathrm{OR}=0.57$ for each $\mathrm{SD})$ or higher IES-R avoidance score $(\mathrm{OR}=0.70$ for each SD) had lower chances to be back at work.

The Hosmer-Lemeshow statistic provided no strong evidence that the final model failed at predicting the data $\left(\chi^{2}=393.92, \mathrm{df}=392, p=0.463\right)$. The final model's apparent c statistic was 0.78 while the optimism-corrected c statistic, calculated with 200 bootstrap resamples, was 0.69 .

\section{Discussion}

In the present study, we observed that good perception of general health and low pain may predict a higher RTW 2 years after a rehabilitation program. These results confirm those of others for pain [7, 27-29] and self rated health $[30,31]$. Moreover, in accordance with earlier results [17, 18] changes in pain and perceived health, during hospitalisation, were also predictors of RTW. It means that, among patients with an identical initial pain, those who experience a larger decrease in pain during hospitalisation are more prone to return to work 2 years later. From these results, it can be hypothesized that an intervention on pain and perceived health may favour return to work but this issue remains to be investigated more thoroughly. A complementary variable to health perception is the perceived severity of the lesion. The present study suggests that patients who believe their lesions are very light to moderate (compared to severe or very severe) have increased likelihood to RTW. These results are compatible with those of others [32].

Among biomedical variables, the demographic factor most commonly found to be associated with chronic disability is older age $[33,34]$ or age below 41 years (and gender [35]). For this reason, these variables were taken as confounders in the present study. The important fraction of male patients (i.e. $81 \%$ ) is expected because these patients 
Table 1 Summary statistics for the confounding variables

\begin{tabular}{|c|c|c|c|c|c|c|c|}
\hline \multirow[t]{2}{*}{ Variable } & \multirow[t]{2}{*}{ Category } & \multicolumn{2}{|c|}{ Admission $(\mathrm{n}=1,207)$} & \multicolumn{2}{|c|}{$\begin{array}{l}\text { 2-year responders } \\
(\mathrm{n}=531)\end{array}$} & \multicolumn{2}{|c|}{$\begin{array}{l}\text { 2-year complete cases } \\
(\mathrm{n}=411)\end{array}$} \\
\hline & & Frequency & $\%$ & Frequency & $\%$ & Frequency & $\%$ \\
\hline \multirow[t]{2}{*}{ Clinic } & RKB & 665 & 55.1 & 290 & 54.6 & 249 & 60.6 \\
\hline & CRR & 542 & 44.9 & 241 & 45.4 & 162 & 39.4 \\
\hline \multirow[t]{2}{*}{ Gender } & Men & 979 & 81.1 & 423 & 79.7 & 336 & 81.7 \\
\hline & Women & 228 & 18.9 & 108 & 20.3 & 75 & 18.3 \\
\hline Age & NA & Mean $=41.4$ & $\mathrm{SD}=10.6$ & Mean $=43.5$ & $\mathrm{SD}=10.2$ & Mean $=43.3$ & $\mathrm{SD}=10.3$ \\
\hline \multirow[t]{2}{*}{ Native language } & Local & 665 & 55.1 & 370 & 69.7 & 296 & 75.0 \\
\hline & Other & 542 & 44.9 & 161 & 30.3 & 115 & 28.0 \\
\hline \multirow[t]{2}{*}{ Marital status } & Single & 569 & 47.1 & 231 & 43.5 & 169 & 41.1 \\
\hline & $\begin{array}{l}\text { Married/ } \\
\text { partnership }\end{array}$ & 638 & 52.9 & 300 & 56.5 & 242 & 58.9 \\
\hline \multirow[t]{3}{*}{ Education } & $\leq 9$ years & 594 & 49.2 & 249 & 46.9 & 203 & 50.6 \\
\hline & $>9$ years & 544 & 45.1 & 253 & 47.6 & 208 & 49.4 \\
\hline & Missing values & 69 & 5.7 & 29 & 5.5 & NA & NA \\
\hline \multirow{3}{*}{$\begin{array}{l}\text { Time between accident and } \\
\text { admission }\end{array}$} & $<12$ months & 481 & 39.8 & 219 & 41.2 & 182 & 44.3 \\
\hline & $>12$ months & 695 & 57.4 & 296 & 55.7 & 229 & 55.7 \\
\hline & Missing values & 34 & 2.8 & 16 & 3.0 & NA & NA \\
\hline \multirow[t]{3}{*}{ Work contract at admission } & Yes & 776 & 64.3 & 368 & 69.3 & 297 & 72.3 \\
\hline & No or not known & 362 & 30.0 & 140 & 26.4 & 114 & 27.7 \\
\hline & Missing values & 69 & 5.7 & 23 & 4.3 & NA & NA \\
\hline \multirow[t]{4}{*}{ Main traumatic localization } & Upper limb & 315 & 26.0 & 137 & 25.8 & 102 & 24.8 \\
\hline & Lower limb & 416 & 34.4 & 206 & 38.8 & 158 & 38.4 \\
\hline & Neck & 207 & 17.1 & 83 & 15.6 & 72 & 17.5 \\
\hline & Low back & 272 & 22.5 & 105 & 19.8 & 79 & 19.2 \\
\hline
\end{tabular}

are mostly blue collar workers victim of work or traffic accidents. It appears from the literature that pain and psychosocial factors are of primary importance to explain long term sick leave [36-38]. Moreover, general health perception and perception of health change/improvement was strongly associated with a duration of sickness absence and with recurrence of new sick leave episodes for the same musculoskeletal complaints [31, 39]. To our knowledge, this is the first study to identify sub scores of the IES$\mathrm{R}$ questionnaire, an indicator of the post traumatic stress disorder (PTSD) (for a review see [40]) as predictors of RTW in patients with traumatic injuries. The cut off value of 33, identifies the PTSD with a sensitivity of 0.91 and a specificity of 0.82 [41]. Interestingly, our population had a high mean total score of the IES-R (i.e. $35 \pm 28$ [SD]). More precisely the IES avoidance (e.g. effortful avoidance of situations that are reminders of the accident) and hyperarousal (e.g. being irritable, having trouble falling asleep, watchful and on guard) was retained in our final model. Apparently, our results are not in accordance with those of Toien et al. [16] who reported that IES was not selected in their model prediction of RTW in trauma patients 1 year after the first assessment. However, in the latter study, the total score of the non revised version of the IES was used, which may be less sensitive to identify intrusion and avoidance [42]. Moreover, total IES-R score may not be appropriate in the prediction of the outcome because each sub-score (i.e. avoidance, hyperarousal and intrusion) may behave differently. For instance, from results of the final minimal model in the present study, patients with hyperarousal problems were apparently more prone to RTW (Fig. 2). These results are surprising because the opposite effect can be expected. However, the non-adjusted simple regression presents an odds ratio of 0.7 for the IES-R hyperarousal score, i.e. a lower likelihood of RTW. To explore this point, models were calculated, containing IES-R hyperarousal plus the confounders and all possible combinations of $1-4$ of the remaining final-model predictors. The OR for IES-R hyperarousal switched from negative to positive only in the presence of the IES-R avoidance variable. Thus, IES-R avoidance seems to be an important confounder of IES-R hyperarousal. Interestingly, clinical practice confirms the possibility of patients with hyperarousal symptoms to develop strategies compatible 
Table 2 Summary statistics for the predictive variables

\begin{tabular}{|c|c|c|c|c|c|c|c|c|c|c|c|c|}
\hline \multirow{2}{*}{\multicolumn{2}{|c|}{ Variable }} & \multirow[t]{2}{*}{ Category } & \multicolumn{3}{|c|}{ Admission $(\mathrm{n}=1,207)$} & \multicolumn{4}{|c|}{$\begin{array}{l}\text { 2-year responders } \\
(\mathrm{n}=531)\end{array}$} & \multicolumn{3}{|c|}{$\begin{array}{l}\text { 2-year complete cases } \\
(\mathrm{n}=411)\end{array}$} \\
\hline & & & $\mathrm{n}^{\mathrm{a}}$ & Mean & SD & $\mathrm{n}^{\mathrm{a}}$ & $\mathrm{Me}$ & & SD & Mean & SD & \\
\hline \multicolumn{2}{|l|}{ General health at admission } & NA & 1,198 & 47.8 & 22.0 & 526 & 49. & & 22.1 & 49.1 & 21. & \\
\hline \multicolumn{2}{|c|}{ General health improvement during stay } & NA & 1,025 & 5.4 & 24.6 & 517 & 6. & 9 & 23.4 & 6.7 & 23. & \\
\hline \multicolumn{2}{|l|}{ Pain at admission } & NA & 1,174 & 55.7 & 25.2 & 511 & 52 & & 25.9 & 53.1 & 25 . & \\
\hline \multicolumn{2}{|l|}{ Pain decrease during stay } & NA & 981 & -5.6 & 22.9 & 490 & -5 & & 24.1 & -6.0 & 23. & \\
\hline \multicolumn{2}{|l|}{ HADS anxiety } & NA & 1,196 & 9.1 & 4.5 & 526 & 8 & 6 & 4.4 & 8.6 & 4. & \\
\hline \multicolumn{2}{|l|}{ HADS depression } & NA & 1,196 & 7.4 & 4.5 & 525 & 6 & 9 & 4.3 & 7.0 & 4. & \\
\hline \multicolumn{2}{|l|}{ SF-36 physical summary score } & NA & 1,151 & 33.3 & 7.0 & 503 & 33 & & 7.1 & 32.9 & 6. & \\
\hline \multicolumn{2}{|l|}{ SF-36 mental summary score } & NA & 1,151 & 37.8 & 9.1 & 503 & 39 & & 9.1 & 39.1 & 9. & \\
\hline \multicolumn{2}{|l|}{ IES-R avoidance } & NA & 1,174 & 11.5 & 10.4 & 517 & 10 & & 10.6 & 11.1 & 10. & \\
\hline \multicolumn{2}{|l|}{ IES-R intrusion } & NA & 1,173 & 12.5 & 11.2 & 517 & 11 & & 10.9 & 11.6 & 10. & \\
\hline \multirow[t]{2}{*}{ IES-R hyper-arousal } & & NA & 1,164 & 10.8 & 8.6 & 513 & 10 & & 8.4 & 10.4 & 8 . & \\
\hline & & & & \multicolumn{2}{|c|}{ Frequency } & $\%$ & \multicolumn{3}{|c|}{ Frequency } & $\%$ & Frequency & $\%$ \\
\hline \multirow[t]{2}{*}{ Perceived severity of injury } & \multicolumn{3}{|c|}{ Severe to very severe } & 1,207 & 753 & 62.2 & \multicolumn{3}{|c|}{312} & 58.8 & 248 & 60.3 \\
\hline & \multicolumn{3}{|c|}{ Very light to moderate } & & 457 & 37.8 & \multicolumn{3}{|c|}{219} & 41.2 & 163 & 39.7 \\
\hline \multirow[t]{2}{*}{ Expected outcome } & \multirow{2}{*}{\multicolumn{3}{|c|}{$\begin{array}{l}\text { Deterioration or no improvement } \\
\text { Soon recovered or getting better }\end{array}$}} & 1,207 & \multirow{2}{*}{$\begin{array}{l}381 \\
829\end{array}$} & 31.5 & 531 & \multicolumn{2}{|c|}{146} & 27.5 & 114 & 27.7 \\
\hline & & & & & & 68.5 & & 38 & & 72.5 & 229 & 72.3 \\
\hline
\end{tabular}

${ }^{a}$ All predictors could not be assessed for all patients due to missing values

Table 3 Logistic regressions

\begin{tabular}{|c|c|c|c|c|c|c|c|c|}
\hline \multirow[t]{2}{*}{ Variable } & \multirow[t]{2}{*}{ Category } & \multicolumn{4}{|c|}{$\begin{array}{l}\text { Non-adjusted } \\
\text { (simple regressions) }\end{array}$} & \multicolumn{3}{|c|}{$\begin{array}{l}\text { Fully adjusted } \\
\text { (complete model) } n=411\end{array}$} \\
\hline & & $\mathrm{n}$ & OR & CI $95 \%$ & $\mathrm{P}$ & OR & CI $95 \%$ & $\mathrm{P}$ \\
\hline General health at admission & NA & 526 & 1.66 & $1.26-2.18$ & $<0.001$ & 1.40 & $0.89-2.21$ & 0.149 \\
\hline General health improvement during stay & NA & 517 & 1.19 & $1.02-1.37$ & 0.022 & 1.14 & $0.98-1.33$ & 0.082 \\
\hline Pain at admission & NA & 511 & 0.62 & $0.60-0.64$ & $<0.001$ & 0.61 & $0.57-0.65$ & $<0.001$ \\
\hline Pain decrease during stay & NA & 490 & 1.37 & $1.35-1.39$ & $<0.001$ & 1.69 & $1.47-2.04$ & $<0.001$ \\
\hline HADS anxiety & NA & 526 & 0.64 & $0.49-0.83$ & 0.001 & 0.94 & $0.86-1.02$ & 0.139 \\
\hline HADS depression & NA & 525 & 0.60 & $0.51-0.71$ & $<0.001$ & 1.06 & $0.83-1.36$ & 0.634 \\
\hline SF-36 physical summary score & NA & 503 & 1.48 & $1.15-1.92$ & 0.002 & 1.16 & $0.75-1.76$ & 0.498 \\
\hline SF-36 mental summary score & NA & 503 & 1.41 & $1.40-1.42$ & $<0.001$ & 1.15 & $0.96-1.37$ & 0.123 \\
\hline IES-R avoidance & NA & 517 & 0.69 & $0.51-0.92$ & 0.011 & 0.69 & $0.61-0.79$ & $<0.001$ \\
\hline IES-R intrusion & NA & 517 & 0.70 & $0.52-0.94$ & 0.016 & 1.05 & $0.60-1.84$ & 0.865 \\
\hline IES-R hyper-arousal & NA & 513 & 0.70 & $0.55-0.87$ & 0.002 & 1.32 & $0.76-1.68$ & 0.535 \\
\hline \multirow[t]{2}{*}{ Perceived severity of injury } & Severe or very severe & 312 & 1 & & & 1 & & \\
\hline & Very light to moderate & 219 & 1.97 & $1.11-3.49$ & 0.020 & 1.08 & $1.03-1.14$ & 0.002 \\
\hline \multirow[t]{2}{*}{ Expected outcome } & Deterioration or no improvement & 146 & 1 & & & 1 & & \\
\hline & Soon recovered or getting better & 385 & 2.41 & $1.86-3.13$ & $<0.001$ & 1.14 & $0.78-1.66$ & 0.492 \\
\hline
\end{tabular}

OR for continuous variables refer to one-SD increments

In the fully adjusted model, predictors are adjusted for each other and for the confounding variables (for the final model see Fig. 2)

with professional environment. This empirical experience of our medical staff, which is used to treat patients with PTSD, is compatible with the concept that some hyperarousal behaviour may not be deleterious for RTW.
Moreover, a study performed on Oklahoma city bombing survivors [43] has reported that patients with avoidance behaviour received more mental health treatment, had much more interference with activities and were more 


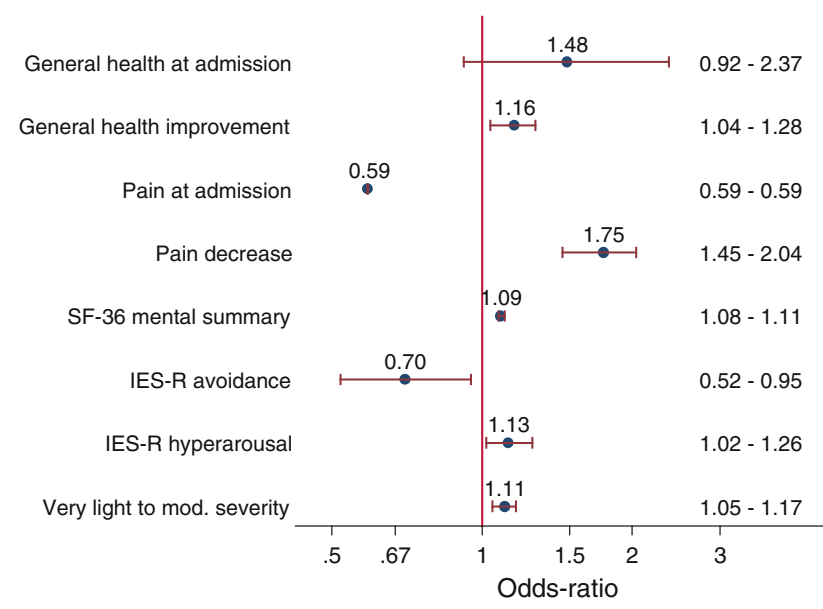

Fig. 2 Confounder-adjusted odds-ratios (OR) and $95 \%$ confidence intervals for the predictors of the final, multivariable, model (see "Methods"); OR for continuous variables refer to increments of one $\mathrm{SD}$. A value over the unity indicates an increased likelihood to return to work. $\mathrm{X}$-axis in logarithmic scale. $\mathrm{N}=411$

dissatisfied with work than those with an hyperarousal behaviour. However, we cannot fully explain our finding and this issue has to be investigated further. Finally, it must be kept in mind that a clinical diagnosis of PTSD cannot be formally determined from the response of the IES-R questionnaire. Consequently, further research should be performed in which trained clinicians may systematically screen this pathology in patients. A 1-year follow-up study performed on patients with back and/or neck pain, found strong associations between pain, expectancy, pain-related fear and a belief in an underlying and serious medical problem [29]. These associations can also be extended to PTSD [44] and are also compatible with the present results. These results suggest that patients' pain care should also involve the treatment of fear avoidance [45], PTSD and some other psychological aspects.

Our prediction of RTW by the SF-36 mental summary is in accordance with the results by Schultz et al. [46] who identified the same variable as predictor of RTW 3 months after injury and with those of Pattani who observed that poor quality of life (especially the mental health component) at baseline and without improvement, predicts return to work [47].

A strength of the present work is the duration of the observation (2 years) because there seem to be a lack of studies with a long follow-up period (i.e. more than 1 year) [48].

The main limitation of this study is the low response rate of the eligible patients 2 years after hospitalisation i.e. $34 \%$. In our study, the descriptive statistics of responder, predictors and confounders were relatively stable through time except for the proportion of local native language speakers. It has been reported that patients with local native language were more prone to RTW [49] and also more likely to respond to questionnaires [19]. This suggests that data were not missing at random and, therefore, loss to follow-up caused some degree of bias in our OR estimations. Furthermore, because the RTW was obviously only assessed from the responders, our results probably overestimate overall RTW proportion and means and proportions of predictor values. Another limitation of this protocol is that these results cannot be extended to all patients with musculoskeletal injuries. However, because only patients with persistent health problems after an accident are hospitalised in our clinic, the results can be useful for this kind of patients who are following treatment for long periods.

Unfortunately, for technical reasons the present study did not assess the working status continuously but only at 2 years by sending questionnaires for the following reasons: some patients did not know the exact date of return to work and continuous follow up was a too demanding protocol. Moreover, the files of our insurance company did not allow finding the date of RTW i.e. only rents and work ability were available. Our patients often exhibit trauma associated with psychological, social and occupational problems, Consequently, it is not surprising that an important fraction of those patients did not return to work after 2 years.

In conclusion, this study assessed predictors of RTW on patients with musculoskeletal injuries 2 years after a rehabilitation program. Patients who reported a higher general health perception and a low pain at the start of rehabilitation period as well as those who exhibit a large general health improvement and pain decrease during rehabilitation were more prone to return to work. Conversely, individuals who presented avoidance behaviour had a low probability to return to work. Our findings suggest that rehabilitation interventions should also depend on the patient general health perception as well as pain and fear-avoidance beliefs related to the accident.

Open Access This article is distributed under the terms of the Creative Commons Attribution License which permits any use, distribution, and reproduction in any medium, provided the original author(s) and the source are credited.

\section{References}

1. Hazard RG, Haugh LD, Reid S, Preble JB, MacDonald L. Early prediction of chronic disability after occupational low back injury. Spine (Phila Pa 1976). 1996;21:945-51.

2. Clay FJ, Newstead SV, McClure RJ. A systematic review of early prognostic factors for return to work following acute orthopaedic trauma. Injury. 2010;41:787-803.

3. Schultz IZ, Stowell AW, Feuerstein M, Gatchel RJ. Models of return to work for musculoskeletal disorders. J Occup Rehabil. $2007 ; 17: 327-52$. 
4. Schultz IZ, Crook J, Fraser K, Joy PW. Models of diagnosis and rehabilitation in musculoskeletal pain-related occupational disability. J Occup Rehabil. 2000;10(4):271-93.

5. Turk DC, Monarch ES. Biopsychosocial perspective on chronic pain. In: Turk DC, Gatchel RJ, editors. Psychological approaches to pain management. A practitioner's handbook. 2nd ed. New York: Guilford; 2002.

6. Fadyl JK, McPherson KM, Schluter PJ, Turner-Stokes L. Factors contributing to work-ability for injured workers: literature review and comparison with available measures. Disabil Rehabil. 2010;32:1173-83.

7. Cheng JC, Li-Tsang CW. A comparison of self-perceived physical and psycho-social worker profiles of people with direct work injury, chronic low back pain, and cumulative trauma. Work. 2005;25:315-23.

8. Crombez G, Vlaeyen JW, Heuts PH, Lysens R. Pain-related fear is more disabling than pain itself: evidence on the role of painrelated fear in chronic back pain disability. Pain. 1999;80:329-39.

9. Vlaeyen JW, Haazen IW, Schuerman JA, Kole-Snijders AM, van Eek H. Behavioural rehabilitation of chronic low back pain: comparison of an operant treatment, an operant-cognitive treatment and an operant-respondent treatment. Br J Clin Psychol. 1995;34(Pt 1):95-118.

10. Vlaeyen JW, Kole-Snijders AM, Boeren RG, van Eek H. Fear of movement/(re)injury in chronic low back pain and its relation to behavioral performance. Pain. 1995;62:363-72.

11. Turner JA, Franklin G, Fulton-Kehoe D, et al. Worker recovery expectations and fear-avoidance predict work disability in a population-based workers' compensation back pain sample. Spine (Phila Pa 1976). 2006;31:682-9.

12. Aaron DL, Fadale PD, Harrington CJ, Born CT. Posttraumatic stress disorders in civilian orthopaedics. J Am Acad Orthop Surg. 2011;19:245-50.

13. Grunert BK, Devine CA, McCallum-Burke S, Matloub HS, Sanger JR, Yousif NJ. On-site work evaluations: desensitisation for avoidance reactions following severe hand injuries. J Hand Surg Br. 1989;14:239-41.

14. Opsteegh L, Reinders-Messelink HA, Schollier D, et al. Determinants of return to work in patients with hand disorders and hand injuries. J Occup Rehabil. 2009;19:245-55.

15. Dyster-Aas J, Kildal M, Willebrand M. Return to work and health-related quality of life after burn injury. J Rehabil Med. 2007;39:49-55.

16. Toien K, Skogstad L, Ekeberg O, Myhren H, Schou Bredal I. Prevalence and predictors of return to work in hospitalised trauma patients during the first year after discharge: a prospective cohort study. Injury. 2011. doi:10.1016/j.injury.2011.03.038.

17. Hildebrandt J, Pfingsten M, Saur P, Jansen J. Prediction of success from a multidisciplinary treatment program for chronic low back pain. Spine (Phila Pa 1976). 1997;22:990-1001.

18. Vendrig AA. Prognostic factors and treatment-related changes associated with return to work in the multimodal treatment of chronic back pain. J Behav Med. 1999;22:217-32.

19. Burrus C, Ballabeni P, Deriaz O, Gobelet C, Luthi F. Predictors of nonresponse in a questionnaire-based outcome study of vocational rehabilitation patients. Arch Phys Med Rehabil. 2009; 90:1499-505.

20. Zigmond AS, Snaith RP. The hospital anxiety and depression scale. Acta Psychiatr Scand. 1983;67:361-70.

21. Ware JE, Snow KK, Kosinski M, Gandek B. SF-36 health survey: manual and interpretation guide: The Health Institute, New England Medical Center. 1993.

22. Horowitz M, Wilner N, Alvarez W. Impact of Event Scale: a measure of subjective stress. Psychosom Med. 1979;41:209-18.

23. Weiss D, Marmar C. The Impact of Event Scale-revised. In: Keane JPWTM, editor. Assessing psychological trauma and
PTSD: a handbook for practitioners. New York: Guilford Press; 1997. p. 399-411.

24. Royston P, Ambler G, Sauerbrei W. The use of fractional polynomials to model continuous risk variables in epidemiology. Int $\mathrm{J}$ Epidemiol. 1999;28:964-74.

25. Hosmer DW, Lemeshow S. Applied logistic regression. WileyInterscience; 2000.

26. Harrell FE Jr, Lee KL, Mark DB. Multivariable prognostic models: issues in developing models, evaluating assumptions and adequacy, and measuring and reducing errors. Stat Med. 1996;15: 361-87.

27. Andersen LL, Mortensen OS, Hansen JV, Burr H. A prospective cohort study on severe pain as a risk factor for long-term sickness absence in blue- and white-collar workers. Occup Environ Med. 2011;68:590-2.

28. Atroshi I, Andersson IH, Gummesson C, Leden I, Odenbring S, Ornstein E. Primary care patients with musculoskeletal pain. Value of health-status and sense-of-coherence measures in predicting long-term work disability. Scand J Rheumatol. 2002;31: 239-44.

29. Boersma K, Linton SJ. Expectancy, fear and pain in the prediction of chronic pain and disability: a prospective analysis. Eur $\mathbf{J}$ Pain. 2006;10:551-7.

30. Post M, Krol B, Groothoff JW. Self-rated health as a predictor of return to work among employees on long-term sickness absence. Disabil Rehabil. 2006;28:289-97.

31. Schultz IZ, Crook J, Meloche GR, et al. Psychosocial factors predictive of occupational low back disability: towards development of a return-to-work model. Pain. 2004;107:77-85.

32. Gauthier N, Sullivan MJ, Adams H, Stanish WD, Thibault P. Investigating risk factors for chronicity: the importance of distinguishing between return-to-work status and self-report measures of disability. J Occup Environ Med. 2006;48:312-8.

33. Crook J, Moldofsky H, Shannon H. Determinants of disability after a work related musculetal injury. J Rheumatol. 1998;25:1570-7.

34. Infante-Rivard C, Lortie M. Prognostic factors for return to work after a first compensated episode of back pain. Occup Environ Med. 1996;53:488-94.

35. Lötters F, Burdorf A. Prognostic factors for duration of sickness absence due to musculoskeletal disorders. Clin J Pain. 2006; 22(2):212-21.

36. Schultz IZ, Crook J, Meloche GR, et al. Psychosocial factors predictive of occupational low back disability: towards development of a return-to-work model. Pain. 2004;107(1-2):77-85.

37. Crook J, Moldofsky H. The clinical course of musculoskeletal pain in empirically derived groupings of injured workers. Pain. 1996;67(2-3):427-33.

38. Crook J, Milner R, Schultz IZ, Stringer B. Determinants of occupational disability following a low back injury: a critical review of the literature. J Occup Rehabil. 2002;12(4):277-95.

39. Lotters F, Hogg-Johnson S, Burdorf A. Health status, its perceptions, and effect on return to work and recurrent sick leave. Spine (Phila Pa 1976). 2005;30:1086-92.

40. Sundin EC, Horowitz MJ. Impact of Event Scale: psychometric properties. Br J Psychiatry. 2002;180:205-9.

41. Creamer M, Bell R, Failla S. Psychometric properties of the Impact of Event Scale—revised. Behav Res Ther. 2003;41:1489-96.

42. Beck JG, Grant DM, Read JP, et al. The impact of event scalerevised: psychometric properties in a sample of motor vehicle accident survivors. J Anxiety Disord. 2008;22:187-98.

43. North CS, Nixon SJ, Shariat S, et al. Psychiatric disorders among survivors of the Oklahoma City bombing. JAMA. 1999;282:75562.

44. Roth RS, Geisser ME, Bates R. The relation of post-traumatic stress symptoms to depression and pain in patients with accidentrelated chronic pain. J Pain. 2008;9:588-96. 
45. Godges JJ, Anger MA, Zimmerman G, Delitto A. Effects of education on return-to-work status for people with fear-avoidance beliefs and acute low back pain. Phys Ther. 2008;88:231-9.

46. Schultz IZ, Crook J, Berkowitz J, Milner R, Meloche GR. Predicting return to work after low back injury using the Psychosocial Risk for Occupational Disability Instrument: a validation study. J Occup Rehabil. 2005;15:365-76.

47. Pattani S, Constantinovici N, Williams S. Predictors of reemployment and quality of life in NHS staff one year after early retirement because of ill health; a national prospective study. Occup Environ Med. 2004;61:572-6.

48. Soberg HL, Finset A, Bautz-Holter E, Sandvik L, Roise O. Return to work after severe multiple injuries: a multidimensional approach on status 1 and 2 years postinjury. J Trauma. 2007; 62:471-81.

49. Luthi F, Stiefel F, Gobelet C, Rivier G, Deriaz O. Rehabilitation outcomes for orthopaedic trauma individuals as measured by the INTERMED. Disabil Rehabil. 2011;33(25-26):2544-52. 